\title{
Argument Evaluation Contest Results
}

In Vol. XI, No. 1, this journal announced an argument analysis contest. Two eminent colleagues agreed to serve as judges-Professor Henry W. Johnstone, Jr. and Professor Michael Scriven. In short order, four entries were received and sent off to the judges, who had no knowledge of the contestants' identities, and in due course the judges' verdicts were delivered.

Immediately below we have reproduced the argument which was to be analyzed, along with the rules of the contest, followed by the four entries. Thereafter we present the judges' rulings.

\section{Employment Equity in Canada}

RULES (1) The critique should be addressed to a reasonably well-informed, non-specialist, general public. (2) The merits as well as the defects of the argumentation should be discussed. (3) Length must not exceed 1,500 words. (4) The judges will be selected by the editors. Their names will be announced when the winner has been selected. (5) The winning entry will be published in INFORMAL LOGIC. (6) Entries will be blind refereed. Authors must not identify themselves on their entries; only on an accompanying letter giving their name, affiliation if any, and complete mailing address. (7) The judges' decision will be final. (8) We reserve the right not to award the prize if in the opinion of the judges no suitable submissions are received. (9) Entries must be postmarked no later than June 1, 1990.

Background: By the end of 1989, critics alleged that the results of the Canadian government's 1986 employment equity program were abysmal; women, minorities, aboriginal peoples and the disabled had made little progress in entering the labour force. The following argument has been adapted from a presentation in a public debate on the issue.

Recent statistics suggest that Canadians don't believe in equal opportunity for disabled people. Of the 14 percent of Canadians who are disabled but employable, 50 to 80 percent are unemployed. Most of these have short-term, low-wage jobs. These statistics scare me: because of an auto accident, I am confined to a wheelchair.

Although it is mandatory, the federal employment equity program has no specified benchmarks and it covers less than $5 \%$ of the workforce. Most other equity programs around the country are voluntary, What we need is effective, mandatory employment equity legislation. Employers must be forced to hire and promote people regardless of their gender, race or disability, and should have to meet employment targets roughly equal to the percentage of each disadvantaged group in the population. If they don't comply, they should face heavy penalties.

Mandatory programs don't require reverse discrimination. I don't want to be hired just because I' $m$ in a wheelchair, but I don't want to be rejected for that reason either. Such discrimination exists. How else do you explain that a 1982 study showed 97 per cent of able-bodied university graduates were employed, but only $75 \%$ of disabled university graduates were employed?

If there isn't explicit discrimination-like the time I was told point blank, "the company doesn't hire the disabled" - then, and more often, it is unthinking discrimination. If a building has no wheelchair access, I can't even make it to the interview.

Despite the best intentions, voluntary employment equity programs haven't worked. Women, visible minorities, natives and the disabled-the groups supposed to benefit from these programs - have not made appreciable gains. But in the U.S. mandatory programs have made a big difference for women and minorities. So, until attitudes of discrimination against these groups disappear, mandatory employment equity programs will be needed.

It is true, as critics point out, you cannot legis- 
late changes in attitudes. But you can legislate changes in practices, and from experience with non-discriminatory practices, new non-discriminatory attitudes will emerge. For instance, there have been studies which show that employers who have hired one disabled person are more likely to hire others.

Strong employment equity programs will ben- efit everyone. The disadvantaged will gain self esteem and economic independence. Employers will gain dedicated employees. Taxpayers will see a reduction in social services costs. Most important, the disadvantaged will gain their right to be recognized as valued members of the society Remember this: just as I didn't ask to be hit by a drunk driver, it could happen to you.

\section{Entry 121: Employment Equity in Canada}

\section{JONATHAN ADLER Brooklyn College, CUNY}

The main conclusion of the argument is that $[\mathbf{C}]$ Canada needs "effective, mandatory employment equity legislation."

\section{Analysis}

The premises are best organized into four categories: Positive reasons; Criticism of alternatives; Response to objections; and Drawing the conclusion.

\section{A. Positive reasons.}

1. Assumed premise [AP]: Equal opportunity for all citizens regardless of gender, race, or disability is a basic ideal.

2 . There is discrimination against the disabled [of a kind that violates Al].

\section{Evidence for $\mathrm{A} 2$ :}

a. "Of the 14 percent of Canadians who are disabled but employable, 50 to 80 percent are unemployed. Most of these have lowwage jobs."

b. "...a 1982 study showed 97 per cent of able-bodied university graduates were employed, but $75 \%$ of disabled university graduates were employed...."

c. There is explicit discrimination.

d. There is also "unthinking discrimination."

4. "...in the U.S. mandatory programs have made a big difference for women and minorities."

5 . There will be overall gains to everyone from this legislation:

a. The disadvantaged will gain self-esteem, economic independence, and their "right to be recognized as valued members of the society."

b. "Employers will gain dedicated employees."

c. "Taxpayers will see a reduction in social service costs."

d. A disabling accident or illness can befall anyone.

$B$. Inadequate alternatives.

6. The current mandatory "program has no specified benchmarks and it covers less than $5 \%$ of the workforce."

7. "Voluntary employment equity programs haven't worked."

8. The main evidence for $B 7$ is that the relevant groups have not made "appreciable gains."

C. Response to objections.

9. Mandatory programs don't require reverse discrimination.

10. a. Attitudes can be changed as a result of altering practices.

b. Evidence cited is of studies which show that employers who "hire one disabled person are more likely to hire others."

D. Drawing the conclusion.

11. $[\mathrm{AP}]$ The alternatives criticized $(6,7)$ are the only realistic alternatives. That is, no other alternative but "effective, mandatory employment equity legislation" promises to help realize the ideal of equal opportunity, so long as attitudes of discrimination remain. 
12. $1,2 \& 3,4,5$ provide reinforcing, but distinct, support for 13 .

Therefore, we should accept 13. [C]

\section{Discussion}

1. A. Unless one introduces contrived premises, the argument must be taken as aiming to strongly support its conclusion, though not to imply it conclusively (or validly). Specifically, no grounds are offered for the crucial assumed premise (D11) that no alternative programs are possible. Nor is it shown that there are no disadvantages to the proposed legislation with regard either to the ideal of equal opportunity or other ideals (e.g. economic advancement) that the society may legitimately have.

$B$. The conclusion is very strong, especially given the author's interpretation in the two sentences following the conclusion (para. 2). It proposes not a guideline, but a statistical criterion to judge employment practices. Nor is the criterion one of intention-of demonstrating a good faith effort-but of results. For the heavy penalties are imposed when one fails to meet the criterion, regardless of efforts.

C. The author does not, but should, qualify "population" (para.2) by "relevant population." Since, if not, it would allow those disabled without minimal qualifications for a position to count for the target criterion. That would go beyond even the reverse discrimination which the author rejects.

\section{Assumed premises.}

Al: The whole argument depends upon our accepting the ideal of equal opportunity. (See the opening sarcastic sentence). If this ideal is rejected, the proposal doesn't even get off the ground no matter what the evidence. Thus, if an employer has complete control over hiring, as on a libertarian view, neither actual nor potential discrimination is evidence of wrongdoing.

D1 1: Some assumption like this must be made for the conclusion to be drawn that the proposed legislation should not merely be considered but should actually be approved.

\section{Evaluation}

\section{General.}

a. We are not told the forum in which the argument is presented, nor do we know much about the context. If there are strict requirements of brevity (e.g. a letter to the editor), we should extend greater charity concerning alternative objections or possibilities that the author does not mention. Contextual information would help us determine what assumptions the author is entitled to.

b. Little in the passage is argumentatively superfluous. Virtually everything said is relevant to drawing the conclusion. Presentation is clear. For purposes of argumentative assessment it is not perspicuously organized, and it is in that area that my analysis is most intrusive.

c. The 1982 study must be construed as supporting only $\mathrm{A} 2$, but not as showing the failure of the government's $19 \underline{86}$ program.

\section{Positive.}

a. The opening statistic might be questioned exactly along the lines of my objection 3a below: Not all the differentials in employment need be differentials due to unjust discrimination. But that objection is partly answered by the extent of the differential. The fact is that the numbers are just too large to be accounted for merely by disqualifications due to disabilities.

b. The connection between practices and attitudes is worth emphasizing. For the fact that we lack freedom of mind when it comes to our attitudes is too often used as an excuse for doing nothing.

c. The very final remark, though seeming to be a desperate bit of rhetoric, is not to be dismissed, although the author gives it the wrong emphasis. The author offers it as a prudential reason, rather than a basis for self-criticism. Unless we actively put our- 
selves in place of someone who is disabled, we will find it hard to gain some distance from our own biases. It also helps us to recognize our own discomforts with disabled persons-a recognition relevant to appreciating the pervasiveness of the discrimination.

d. Most of the major claims are supported by plausible reasons or evidence $[A 2, A 3 a-b, B 7]$ or are independently credible or commonly accepted (though their significance is open to question) $[\mathrm{A} 1, \mathrm{~A} 3 \mathrm{c}-\mathrm{d}, \mathrm{A} 4, \mathrm{~B} 6, \mathrm{ClOa}]$.

\section{Negative.}

a. The most glaring difficulty is that the author does not consider the possibility of just discrimination against the disabled. (Note my qualification of premise A2,) That suggests that the author believes that hardly any such discrimination exists or is possible. But some disabilities do justly disqualify persons from certain positions. Of course, anyone of good sense will admit that there is discrimination against the disabled, and that it is often unjust discrimination-discrimination unrelated to qualifications. But not all of it is, and we need a (quantitative) sense of the relations between types of jobs and types of disabilities in order to evaluate the argument and, in particular, some of the evidence (e.g. that $97 \%$ of able-bodied university graduates were employed, but only $75 \%$ of disabled university graduates were employed) [R*-see 4 below].

b. Correlatively, the author does not consider whether there are any consequences of being disabled that might make that population less employable in the absence of discrimination. For example, might there not be a loss of ambition, or a greater tendency to depression and related psychological problems? We need evidence on this question $[R]$. Notice even if the evidence shows that there are such consequences, nothing significant immediately follows. For one might argue that it is part of the ideal of equal opportunity to diminish the impact of these consequences. c. The comparisons with the U.S. programs may be assuming, wrongly, that those programs are more like the author's proposal than any of the alternatives. (The author assumes also that the problem of discrimination in the two countries is similar.) [R]

d. In the case of current mandatory programs the evidence of how bad discrimination is currently doesn't show that there has not been significant improvements, and in the case of voluntary programs a lack of improvement is only asserted. We need data on the prior situation [R].

e. The author ignores almost all the worries about such programs that have been offered in good faith: the costs of administration, the economic effect of non-purely merit hiring, the fact that the employers and the discriminators may not be identical, the (in)justice to members of groups not favored by such legislation, the effect on self-esteem of being hired under such programs, or the way programs like this do lead, in practice, to reverse discrimination. The final paragraph suggests numerous benefits, but the author does not weigh these against the potential costs.

\section{4.* Matters requiring investigation. \\ Marked with an $[R]$ in the evaluation.}

\section{Overall evaluation.}

The author succeeds at demonstrating both that there is a very serious continuing problem of discrimination against the disabled and that the legislation proposed is a serious candidate for consideration. The author offers us not only varied and credible grounds for the proposal, but shows inadequacies in alternatives and responds to some important objections. However, the author does not succeed at justifying its acceptance, given the criticisms, especially $3 a, b$ and $e$. 


\section{Entry 123: Critical Argument Analysis: "Employment Equity in Canada"}

\section{RICHARD FULKERSON East Texas State University}

\section{Diagrammatic Analysis of the Argument}

"Employment Equity in Canada" turns on the following major propositions:

1. The level of unemployment of the disabled in Canada is high.

2. Unemployment of the disabled is a social evil.

3 . The unemployment results from prejudice.

4. Current federal laws and voluntary equity programs can not remove the problem.

5. An anti-discrimination law for sex, race, and condition of disability is needed.

6. Such programs work, i.e., remove the problem.

7. Such programs do not require reverse discrimination.

8. Canada should pass a mandatory federal anti-discrimination law.

The relationships among most of these propositions can be put in a now traditional visual diagram in which each arrow can be read as "therefore it follows":

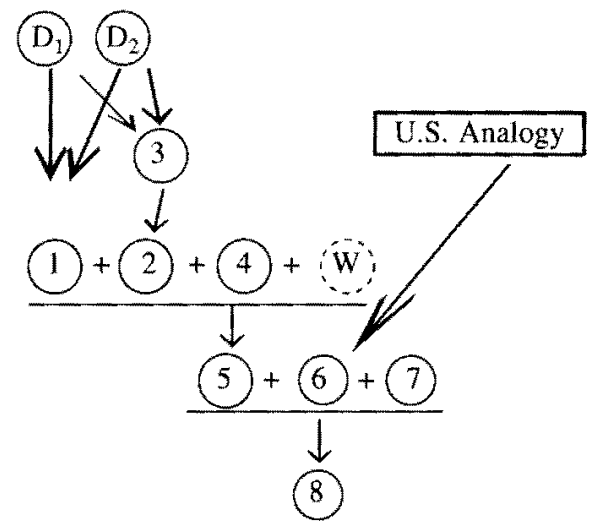

$\left[D_{1}\right.$ and $D_{2}$ represent the two sets of statis- tical data, and $W$ represents an unstated warranting premise; these are discussed further below.]

The arguer's major claim/conclusion $(\# 8)$ is quite clear: Canada should adopt a form of mandatory employment equity legislation, a law that would force employers in the public sector to hire and promote employees "regardless of their gender, race or disability," but also require that workforces reflect the proportions of these minorities in the Canadian population.

Sub-claim (\#5) is supported jointly by (\#1) the high level of unemployment among the disabled, (\#2) the evil of such a situation, (\#4) the failure of current law, and an unstated proposition [W] that when an evil unaddressed by current law exists in a democratic society and a national remedy exists, that remedy should usually be made law.

However, this warranting assumption has known limitations, e.g., "unless the proposed rule violates some guaranteed rights" or "unless the proposed rule causes harm to others," limitations which allow possible exceptions to the claim. The speaker is aware of these exceptions and uses Proposition \#7 to counter the possible objection that such a law would enact quotas and thus violate the rights of others and lead to harms. This sub-argument is difficult to diagram with arrows. The arguer apparently grants that if quotas resulted, that would be undesirable and a reason for rejecting his or her plan, but then argues that quotas will not result. Thus indirectly \#7 helps support \#8.

The high level of unemployment (\#1) is supported by statistics, represented by $D_{1}$ and $D_{2}$. And that such programs do work (\#6) is argued on the basis of an analogy with the U.S. Proposition \#3 can be seen either as an explanation of the condition of high 
unemployment, or as evidence that it is indeed evil on the grounds of an unstated assumption that prejudicial hiring is evil.

\section{Weaknesses in the Argument}

1. Inadequate premises for the claim: The speaker asserts (as clarification of the final claim) that the employers should have to meet employment targets roughly equal to the percentage of each of three disadvantaged groups in the population. It is not clear that the three features to be ignored (gender, race, and disability) all define disadvantaged groups since propositions [1] through [4] at best prove only prejudice against the disabled. We have a non sequitur.

A charitable interpretation, however, might suggest that this text exists in a rhetorical context of ongoing argumentation: many hearers would grant either that racial and gender employment bias is extensive in Canada, or that if it were then by analogy it should be dealt with in the same way as bias against the handicapped.

2. Internal contradiction and equivocation over quotas: More important, the claim that employers should be required to ignore gender, race, and disability conflicts with the "explanation" that employers should have to hire a percentage of each group equivalent to that group's percentage of the population. If an employer were found in violation for hiring, let us say, no women, and were ordered to comply ("forced"), then the future hires would necessarily not ignore gender, and would in fact constitute a quota for the employer to meet before being able to hire others. "Equal opportunity" is a fine-sounding glittering generality-but when the speaker also calls for percentage equivalents and rigorous enforcement, that necessarily leads to reverse discrimination in future hiring, at least until the acceptable percentages are achieved.

3. Misuse of statistics: Two sorts of statistical information are used to show both employment prejudice against the disabled and high levels of unemployment. Without a specific definition of what "disabled" means, and without giving the source of the data, the speaker asserts that $14 \%$ of Canadians are "disabled but employable" but $50 \%$ to $80 \%$ of this group is unemployed. (Some of them, of course, may not even be seeking employment-such as disabled college students.) The range of $50 \%$ to $80 \%$ is rather broad, and might lead one to doubt the dependability of the figures (especially since the next sentence seems to refer to this same group as being employed but in short-term, low-wage jobs; there is a verbal slip here somewhere). And it isn't possible to say what the real situation is without external data. If even $50 \%$ of the $14 \%$ of Canadians are unemployed, it would mean that Canada has an overall unemployment rate of $7 \%$ just from the disabled, not to mention those out of work for other reasons, including discrimination against them as women or ethnic minorities. (If $80 \%$ of $14 \%$ is used, the figure becomes even higher. So high, indeed, as to be hard to believe in an industrialized economy not suffering from severe depression.)

The second set of statistics is handled much worse. The 1982 data about college graduates is too old to be of much value in 1989 , especially since the data comes from four years before the 1986 equity legislation was passed. In addition, the speaker commits the classic material fallacy of interpreting correlation as causation. He or she moves from the correlation between disabilities and lower employment rates for college graduates to the assertion that the disabled are employed at a lower rate because of their disabilities. But this is fallacious: the correlation would show causation by Mills' Method of Agreement and Difference only if the two groups were alike in all other potentially relevant ways: e.g., in college grade averages, in distribution in various major fields, in previous job experience, in participation in campus activities, sex, race, etc. (By the way, if 
only $25 \%$ of disabled college grads are unemployed, while $50 \%$ to $80 \%$ of all the disabled are unemployed, this may suggest that a major reason for the unemployment is inadequate education of the disabled.)

Moreover, the rhetorical question leading into this data ("How else do you explain") begs the very question that needs to be dealt with - whether other explanations exist. It attempts to shift the burden of proof to the opposition, to make them supply another explanation rather than showing that only the disabilities can explain the differential.

5. Another problem is the argument by analogy from the experiences of the United States. The speaker asserts without proof that U.S. mandatory programs have "made a big difference" for women and minorities. Of course that doesn't mention the disabled; but more importantly, the programs in the United States have often been accused of not making much of a difference, and they are not mandatory for all businesses anyway, nor do they include "employment targets" equal to the proportion of the disadvantaged group in the population. Thus even if the two countries are approximately analogous, the laws in the U.S, are not analogous to the law being proposed.

\section{Overall Evaluation}

Is it a good argument? Its overall pattern conforms to those features generally taken as constituting a prima facie case for a deliberative argument over public policy. That is, the speaker attempts to demonstrate that a problem exists, and then calls for a law that seems to match the problem without creating too many new problems of its own. It's also a very short presentation, and one can't fairly ask for elaborate and extensive statistical detail under such conditions.

A lot depends on who is being addressed and what assumptions they are willing to grant. Most audiences would probably grant that prejudice exists against the handicapped. Other things being equal, most companies would probably prefer to hire someone not in a wheelchair to someone in a wheelchair. And that makes life painful for the handicapped, which most audiences would acknowledge to be an evil.

But a skeptical audience would not accept that the problem's extent has been satisfactorily shown. More importantly they could agree about the end and still reject mandatory federal legislation, because it does seem to call for quotas and its practicality is supported only weakly by the analogy with the U.S. The call for a compulsory federal law might be effective in an oral context because of the speaker's ethos and pathos, but the logos is still weak. Using Chaim Perelman's view that the quality of an argument can be assessed by the quality of the audience who would find it convincing, this isn't a strong argument.

RICHARD FULKERSON

DEPARTMENT OF LITERATURE AND

LANGUAGES

EAST TEXAS STATE UNIVERSITY

EAST TEXAS STATION, COMMERCE, TX 75428

\section{Entry 125: Critical Analysis}

\section{MARIE SECOR Penn State University}

The defects of the argument on employment equity in Canada exist mostly at the propositional level; its strengths, less apparent, are evident primarily at the level of issual and enthymemic macrostructure. The pathetic element is of mixed effective- 
ness. The issue for analysis and critique is which level is most important for evaluation.

First, let's look at the logical macrostructure of the argument at the paragraph level. The first paragraph says, in effect, that "we have a problem." That is, many disabled Canadians are unemployed. The claim is supported by some statistical evidence: 50 to $80 \%$ of disabled but employable Canadians are unemployed. By implication, the author may be counted among the unemployed, either now or in the future. Thus the opening paragraph functions to offer exigence, both general and personal, for the argument's proposal thesis.

The second paragraph asserts that present federal programs and other voluntary programs are inadequate. This statement anticipates an objection that might be raised to the first paragraph (that programs already exist) and reinforces the exigence for recommending mandatory federal equity employment programs.

Funneling away from the proposal, as we might expect, are supporting arguments offering reasons for accepting it. Generally, the reasons for taking any action are, potentially, of two kinds: ethical and consequential. Accordingly, the first supporting argument, in paragraphs 3 and 4 , is ethical. Discrimination against the disabled exists, we are told, both direct and "unthinking." This claim tunes into the widely held ethical assumption that discrimination (whether reverse, direct, or unthinking) is a wrong to be rectified. More pragmatically, it implies that the proposal offered will eliminate (not reinforce) discriminatory practices.

The appeal in paragraph 5 is consequential: if voluntary programs have not worked, we need mandatory programs. This formal enthymemic topic is followed by another, in the form of an analogy: if mandatory programs worked in the U.S., they should be tried in Canada.

The penultimate paragraph makes a concession ("you cannot legislate changes in attitude"), and refutes it by reversing causal direction, the writer again employing an enthymemic topic. The final paragraph makes broader consequential arguments ("everyone will benefit") by constructing its audience as segmented but inclusive, consisting of the disabled, taxpayers, and employers. All these constituencies, we are told, will benefit from this proposal. The audience is invited to identify with the writer: not only will the entire body politic benefit, so also will the individual, who is invited to step into the shoes of the disabled author ("it could happen to you").

The above rhetorical analysis identifies the issues and enthymemes offered by the argument. In public discourse, like this argument, proposals derive their exigence from the sense of an existing, shared problem and are supported by ethical and consequential claims, so we can say that this argument, generally, makes the "right" kind of moves. However, one essential element of the proposal is missing: feasibility. What time, money, and people are needed to make this happen? What resistance needs to be overcome? Although this absence of feasibility is a weakness, the overall strength of the argument must be said to lie in its proposal logic, supported by appeal to formal enthymemic topics. Enthymemic topics are probabilistic assumptions about the way the world usually works ("if $x$ doesn't work, try the opposite"; "if causality is seen as going one way, try reversing it"; "what works there may work here"); here, they support the proposal delivered in a deliberative forum. Drawing the audience into the argument is an identification strategy, one whose efficacy is disputable: we, the readers, are taxpayers; we may be employers who might some day benefit from this policy; and any of us could become disabled.

Weaknesses can be identified throughout this argument. From the fact that 50 to $80 \%$ of disabled, employable Canadians are unemployed, it does not follow that 
Canadians do not believe in equal opportunity for disabled people. Further, the Canadian people may care deeply but be unaware of the extent of the problem. Indeed, its extent is unclear; there is a big difference between 50 and $80 \%$ unemployment rates. The basis for the writer's fear of these statistics is only implied; the emotional appeal could be seen as irrelevant. We are told that the present mandatory equity program is inadequate, but no evidence supports that evaluation. The actual proposal, the argument's thesis, is unqualified; we are offered no good reasons why it is the best possible proposal.

Coherence breaks down almost completely in paragraph 3 , and only very charitable reconstruction enables us to read it at all. What looks like a claim expressed in sentence \#l, that such programs do not require reverse discrimination, does not get picked up in the rest of the paragraph. In sentence $\# 2$, the author claims not to want reverse discrimination and that the proposal does not require it, but that personal disclaimer is irrelevant to any determination of whether this program entails it. The fact that only $75 \%$ of disabled university graduates are employed does not demonstrate that discrimination exists, despite the certainty implied by the rhetorical question.

We are told that under voluntary programs, groups like the disabled have not made appreciable gains, but no evidence is offered about actual changes in percentages of employed disabled people. Either we must assume that everyone knows this is true (as the headnote implies), or we are justified in remaining skeptical of the claim. Then comes an analogy with the U.S., where, we are told, mandatory programs have made a big difference. How big? Any analogy, of course, has limitations: social and political conditions in Canada may differ significantly.

The assertion that changes in practice lead to changes in attitude remains unsupported. The proffered example, "employers who hire one disabled person are more likely to hire more," does not support the generalization that such hiring causes attitude changes, for employers may hire because of imperatives other than changed attitudes.

The claim of benefits for all is disputable: the disabled may benefit, but if employers thought that disabled people made good employees, they would probably hire them without mandatory programs, and the cost of administering the program might exceed the cost of social services for the disabled. The final pathetic appeal can be seen as irrelevant: we can empathize with the writer, even fear disability, but still reject the argument.

What we have here is a plausible argument structure at the paragraph level. The fact that it makes the expected large-scale argumentative moves puts it in the ballpark: we recognize the proposal argument and see the general point, whether or not specific supporting claims are well supported. But at the propositional level, the argument falters. Even within space limitations, more relevant statistics could be offered and relationships between premises and conclusions could be more precise. Assuming that this argument is aimed at "a reasonably well-informed, non-specialist, general public"-i.e., a public very much like the audience for this critique-and that such an audience could be counted on to pause and consider the connectedness of what it is asked to accept, then we must judge this argument inadequate.

The issue, really, is what we look at when we evaluate arguments: large-scale structural moves, the way the argument appeals to widely held assumptions, or local connectedness. Hazarding a guess, I suspect that a well-informed, non-specialist general audience will, once the large structure is in place, attend to the local progress, mentally qualifying, rebutting, and reacting as an argument unfolds. As critical readers, we make some big judg- 
ments about plausibility first, then look at details.

Judging hierarchically, I'd say that the lack of supporting evidence for claims is less serious than the sometimes obscure connections between generalizations and examples. As a reasonably but not excessively critical reader, I am willing to accept some claims without evidence: that "voluntary employment equity programs have not worked" and even that unthinking discrimination, like that encountered by the writer, exists. Such assertions are adequate, not spurious, enthymemes; they confirm my general sense of how the world works. But the relationship between the claims and the evidence is more problematic: that raises questions and incites challenge. To say, for instance, that only $75 \%$ of disabled graduates are employed and that the only explanation is discrimination challenges a search for other reasons and seriously weakens the argument.

The emotional appeals appear in the expected places in public discourse, at the beginning and end, where they promote what Perelman calls presence: the disabled person makes present to us his fear and his victimization. Our job as critical readers is to decide whether that awareness is relevant. We may agree that it is important for society to care for the disabled, but conclude that the author is too self-serving and excessively enraged. It seems that the direct revelation of fear and resentment does not reinforce the argument when it depicts the writer as vulnerable and out of control, while the mention of wheelchair access is effective because the author seems purposeful (wanting to get to an interview) but thwarted by circumstances not even noticeable to the insensitive. Mixed grades, then, to the personal notes: the pathetic appeal depicting the writer as competent and purposeful reinforces the ethical appeal, but the spectre of the author's fear and my fear of becoming disabled incites more distaste than identification.

In conclusion, arguments minimally must fulfill the general expectations of reasonable readers, controlling their logical macrostructures and minding their enthymemes. These elements in place, readers respond to inferential patterns, and in public discourse aimed at nonspecialists, the relevance of evidence is more significant than the amount. This argument does not offer enough evidence, but the irrelevance of what it offers is its more serious flaw. Emotional appeals fail if they incite distaste rather than identification. They are most effective when subtly incorporated into the argument (as in the appeal for wheelchair access) rather than obviously appended (as at the end), better when presenting a positive image of the author than a negative one.

MARIE SECOR

DEPARTMENT OF ENGLISH

PENN STATE UNIVERSITY

UNIVERSITY PARK, PA 16802

\section{Entry 127: Employment Equity in Canada}

\section{DAVID HITCHCOCK McMaster University}

"Employment equity" is the current buzzword in Canada for programs designed to make sure that certain groups are justly treated in the job world-in terms of hiring, promotion and pay. Since Judge Rosalie Abela in 1984 identified 
four groups as differentially poorly treated in the Canadian work force-women, "visible minorities" (i.e. non-whites), the disabled, and aboriginal peoples-these groups have become the focus of employment equity and other affirmative action programs. The passage under consideration presents succinctly the main argument for comprehensive mandatory employment equity programs: they are the only effective way to eliminate the unjust discrimination from which their target groups suffer in the workplace.

To deserve support, this argument needs to establish its premiss, in four respects: that the target groups do suffer discrimination in the workplace, that this discrimination is unjust, that no other type of program will end it, and that this type will end it. It also needs defence against the objection that such programs have negative side effects which outweigh any advantages they may provide.

\section{Discrimination against target} groups: The author surprisingly fails to refer to Judge Abela's report or to the statistical evidence on which she based her selection of the four target groups which the author mentions. The author cites evidence only for the group to which he or she belongs, namely, the disabled. The evidence in the first paragraph is garbled. It cannot be true that 14 percent of Canadians are disabled but employable, since almost all children and senior citizens are unemployable, close to half of Canadians are children and senior citizens, and the percentage of Canadian adults between 18 and 65 who are disabled is nowhere near 28 percent (let alone above 28 percent). Whatever the percentage of Canadians who are disabled but employable, however, it is a shocking and striking statistic that 50 to 80 percent of them are unemployed. Shocking as it may be, is the statistic correct? Both the uncomfortably large range and the author's failure to cite a source suggest that it is a speculative estimate. Even if roughly correct, its significance is unclear, since many of the employable disabled Canadians without work may in fact be making no active attempt to seek work; if so, the reasons for their opting out of the labour force would have to be investigated in order to make clear that employable disabled Canadians who looked for work would be less likely to find it than their able-bodied counterparts. Finally, the claim that most of the unemployed Canadians who are disabled but employable have shortterm, low-wage jobs is self-contradictory, and evidently a slip from the claim that most employed disabled Canadians have short-term, low-wage jobs. Again, this claim would have more weight if its source were cited. Both it and the previous claim need supplementing with comparisons to employable able-bodied Canadians to establish the claim of discrimination.

A more telling statistic, in fact, is the comparison later in the passage between employment rates among able-bodied and disabled Canadian university graduates. The author does not give the details of the 1982 study which he or she cites as support. Such a study is most likely to have been done by a public agency such as Statistics Canada, using defensible sampling, questionnaire design and interviewing techniques, and therefore to provide a good basis for thinking that the conclusion is approximately correct.

Injustice of this discrimination: Is this discrimination unjust? Inequality of outcome does not necessarily mean inequality of opportunity. Let us grant that a smaller than average percentage of employable members of these target groups are employed, and a larger than average percentage of employed target group members are in short-term or lowwage jobs. The reason need not be that individuals or the system discriminate unfairly against them on the basis of their membership in the target group. Rather, they may lag behind because their members are less likely to be equally or better qualified candidates for jobs or promotions. To 
raise this possibility in the public arena could be inflammatory, but a comprehensive argument for mandatory employment equity needs to address it. Besides pointing to differences of outcome, those who claim unjust discrimination must rebut evidence or argument that other factors than target group membership account for the difference, and will strengthen their case with well-designed studies showing the same difference of outcome even after controlling for factors obviously relevant to hiring, promotion or pay.

The author's comparison among university graduates controls for educational level, and does strongly suggest, as the author claims, that employers discriminate unjustly against the disabled. More powerful than this statistical comparison, however, is the author's anecdotal evidence. The author is confined to a wheelchair as the result of a car accident caused by a drunk driver; as this presentation shows, he or she is articulate and reasonably welleducated, and thus a promising candidate for many jobs. For such a person to be told point blank that a company doesn't hire the disabled, or to discover that a job is located in a building with no wheelchair access, is to suffer unjust discrimination on the basis of his or her disability. By themselves, such isolated anecdotes would not establish a pattern of unjust discrimination; in conjunction with the statistical evidence, they do. The author's appeal to his or her personal experience is a rhetorically powerful thread interwoven with the argument. But it is more than that. It is an argument by showing, an ostensive demonstration that qualified disabled Canadians suffer unjust discrimination in the workplace.

Alternatives and Effectiveness: The only alternative which the author considers to mandatory employment equity is voluntary employment equity. The limitation is perhaps defensible on the ground that such other measures as employment standards, collective bargaining rights, and human rights laws have been in place for some time and the pattern of unjust discrimination still exists. It is noteworthy, however, that the two instances of discrimination which the author cites are illegal independently of employment equity programs. The author needs to show why existing human rights laws and requirements for wheelchair access are not enough to overcome the unjust discrimination which the disabled suffer.

The author claims that voluntary employment equity programs, claimed to be typical of provincial jurisdictions in Canada, have made little difference for their target groups, whereas mandatory employment equity programs in the United States have made a big difference. The case would be stronger if we were told how long the two types of programs had been in operation and what the gains were in each case. There is in any case a good independent reason for thinking that voluntary employment equity programs will do little to remedy injustice: with no penalty for non-compliance, employers will be lax in establishing and following through on such programs, since they impose a cost on, but provide no benefit to, the employer.

The author concludes from this comparison that mandatory employment equity programs will be needed until discriminatory attitudes disappear. A stronger conclusion in fact follows, that they will be needed until discriminatory attitudes and systemic barriers disappear. Absence of wheelchair access to a building, or of showers and washrooms for women in a factory, are just as powerful barriers to just treatment as prejudiced attitudes.

Response to critics: The author considers only one possible rejoinder by the critics of employment equity programs, that you cannot legislate changes in attitude. The rejoinder is powerful and correct; by legislating changes in behaviour, you can change the behaviour and thus the attitude. Behaviour reflects attitude, but behaviour also influences attitude, as William James pointed out long ago. 
The author fails to consider explicitly the strongest objection to employment equity programs, that by imposing quotas (euphemistically called "targets") they force employers to hire and promote target group members who are less qualified than their competitors, and perhaps even unqualified for the job. Implicitly, however, the author denies this claim. He or she favours mandatory employment targets roughly equal to the percentage of each disadvantaged group in the population. At the same time, the author says that employers must be forced to hire and promote people regardless of race, gender or disability, and denies that mandatory programs require reverse discrimination.

This denial is disingenuous. If Canadian universities, for example, are to be required within a short period of time to have the same percentage of women at each level of employment as there are in the population, they will be unable in the foreseeable future to hire or promote men to any but the lowest level clerical positions. Hiring and promotion will be based on gender, and the excluded men will be victims of reverse discrimination.

Two qualifications must be made to the author's position.

In the first place, the target should be a percentage roughly equal to the percentage in the qualified applicant pool, rather than in the general population. Justice demands, for example, that female $\mathrm{Ph} . \mathrm{D}$. holders who apply for academic jobs have just as good a chance of getting one as male Ph.D. holders. Targets of proportionate representation in academic departments will ensure in the long run that this happens.

But justice does not demand that female Ph.D. holders who apply for academic jobs have an enormously better chance of getting one than male Ph.D. holders. Yet this would be the result if the author's basis for employment equity targets were accepted. Such a more modest target might need to be supplemented by measures to increase the percentage of target group members in the pool of qualified applicants for hiring or promotion. For it may be that attitudinal and systemic barriers are unjustly excluding them from acquiring qualifications or making applications.

In the second place, the author should acknowledge explicitly that mandatory employment equity programs do require reverse discrimination. It is reasonable to draw the line at hiring unqualified applicants-that is, to make employment equity quotas subject to the availability of qualified applicants. But defenders of mandatory employment equity programs must face up to the fact that, in competitive hiring situations like those in the academic world, such programs will lead to hiring candidates who are less well qualified than their competitors. This result is unjust to the better qualified competitors, but the injustice, I would argue, is a price worth paying for remedying the larger injustice of historic and widespread unjust discrimination against the groups targeted by such programs.

The hiring and promotion of less well qualified people as a result of mandatory employment equity programs has another unwelcome result: a loss of self-esteem by members of the target groups who get hired or promoted. Such people do not know whether they got the job or the promotion because they were judged to be the best qualified applicant, or because they were needed to fill a quota. This uncertainty is a blow to one's self-esteem, and is an additional reason why employment equity programs must be subject to the qualification that the successful candidate must be qualified for the job.

The benefits of mandatory employment equity programs are thus more mixed than the author claims. The disadvantaged gain economic independence, but not in all cases self-esteem. Whether employers gain dedicated employees depends on how much the disadvantaged group member realizes and appreciates that the job is an 
opportunity which might otherwise not have arisen. Taxpayers will see no reduction in social service costs unless mandatory employment equity programs increase overall employment, an unlikely result; more probably, such programs will shift the composition of social welfare recipients away from the target groups, without changing the total number.

But, as the author says, the most important benefit will be that the disadvantaged are treated justly. This benefit is an overriding reason for accepting the programs which the author incompletely defends.

DAVID HITCHCOCK

DEPARTMENT OF PHILOSOPHY

MCMASTER UNIVERSITY

HAMILTON, ONTARIO L8S 4KI

\section{Judge's Report}

\section{MICHAEL SCRIVEN Pacific Graduate School of Psychology}

0. The problem was realistic, complex, and important; it provided a serious challenge to professionals and indeed pressed the limits of what can be dealt with in 1500 words. Next time, if there is one, it might be interesting to use a deceptively simple argument, e.g., an ad hominem from the borderland where it's not clear whether it's fallacious or not (Alternative 1). But another complex one would also be very valuable; it seems to me we still have much to learn about such cases (Alternative 2). Indeed, there is so much to be learnt that it would not even be absurd to offer a prize for the best analysis of the same argument, in the light of the published analyses and judges' commentaries (Alternative 3). And one might also move to the metalevel and ask for the best short essay on how to analyze arguments of this kind of length and complexity (Alternative 4). Readers may want to indicate their thoughts about these options to the editors, for the next competition-or, if they have already made that choice, perhaps for a later one.

1. Overview Each of the entrants $[121=1 ; 123=3 ; 125=5 ; 127=7]$ contributed several significant points that no-one else made, and each provided an enlighten- ing and somewhat different perspective on the argument- 1,3 , and 5 were remarkably different. Partly for that reason-that they deserve it and are not duplicative-I suggest that $I L$ publish all of them. But a second consideration for publishing all results seems equally important, namely the importance-for other readers besides the judges-of seeing all of them. Studying these analyses provides some interesting data for work on argument analysis and I am very conscious that the few comments I've made here only scratch the surface of what could come from this, and from similar exercises. (Have there been any others? I believe we lost a great deal from the fact that Analysis only published 'the winning entry' for their competitions.) I hope that there will be some continuing discussion in these pages, including repartee from entrants, commenting either on the other entries or on the judges' procedures, remarks, and recommendations. To do this requires a strong commitment to the discipline of informal logic-it's certainly not enough to be merely committed to the discipline of logic-since doing this runs strongly counter to the mores of the academy. But it's consistent with an absolutely crucial element in IL, namely treating one- 
self as the first subject for critical thinking. In particular, it's an opportunity to further an intensive and valuable discussion of reasoning that we should not allow to slip away - while being a valuable exercise in controlling natural tendencies to bias.

2. Criteria (After or within the description of each criterion, l've underlined a single word to serve as a label for it; in later discussions that word has initial capitals.) Critiquing the passage assigned for the competitors essentially represented a problem in the informal logic sub-field concerned with the analysis of complex arguments. This crucial domain represents the bridge between the kind of problems we usually find in 'baby logic' texts and the kind we find in serious professional journal discussions of difficult issues, e.g., metaethical or philosophical ones. The usual problem with analysis of these problems is that the reader-and sometimes the writer-loses the wood for the trees. Hence, it seemed important to treat as a leading criterion of merit in this competition:

(A) Creating and maintaining not just comprehensibility but clarity of a kind appropriate for the defined audience (defined in the rules as "reasonably wellinformed, non-specialist, general public"), both in the representation of the original argument (A1) and in the analysis and evaluation of it (A2). Here the term 'clarity' is used without presumption of accuracy; the latter consideration is covered in the second criterion. Criterion A2 cut hard against entry 5 , whose technical language would not be understood by that audience; entries 1 and 3 also made reference to Perelman's technical vocabulary, but only peripherally. (Of course, there are arguments and/or decisive elements in the critique of arguments which cannot be made clear to this level of audience without serious misrepresentation; but this example did not seem to involve either category.) Incidentally, 'perspicuity' would probably be a better term than 'clarity', but I'm trying to generate a checklist that would be useful in a classroom and 'perspicuity' lacks perspicuity for many student audiences. Other criteria included:

(B) Portraying the relation of the key elements in the argument to each other accurately -as opposed to clearlyespecially the relation of the main reasons to the intermediate and final conclusions, i.e., producing a plausible account of the structure of the argument. With arguments this complex, there is rarely one right way to represent the structure-certainly not in this case-but there are infinitely many errors.

(C) Correctly identifying any important assumptions (again, many variants of these are allowable, but many others are not).

(D) Providing correct and in most cases explicitly justified criticisms or encomiums of components (inferences, premises, and significant assumptions). This is here called the logical commentary'-although it may include some factual comments-because its function is evaluating the soundness of the logical entity, an argument. (A minor but non-trivial part of Correct is the correct use of any logical terminology employed.)

(E) Distinguishing strong (important) from weak (less important, weak, or trivial) criticisms-'weak' refers to those which could be met by minor concessions or modifications (note how entry 7 does this) - and being selective on the basis of strength in order to meet space and Clarity constraints. (Given the restrictions on length, the criterion Concise, which would normally be independently important, was built into the length requirement.)

(F) Ensuring that the logical commentary is comprehensive in covering the argument's important strengths and weaknesses.

(G) Considering and appropriately evaluating other relevant arguments before drawing an overall conclusion (I take this attempt to get some perspective to be an important part of what distinguishes argument evaluation from bare bones argument criticism, or argument analysis in the narrow sense, a.k.a. traditional logic). 
(H) Assessing the overall organization/ presentation of the original argument visà-vis the intended audience for it-the 'communications commentary' 1 which contrasts with the logical commentary (and would normally subsume the Concise criterion). This was not well covered, but I took that as a sign that in the competition for space, commentary on presentation quality was regarded as less important than logical commentary.

(I) Providing a convincing synthesis of the logical and communications commentary into an overall evaluation of the cogency of the argument. I felt that entry 7 slipped up here, with a conclusion that did not appear to follow well from the balance of the preceding considerations.

(J) There is also originality which may show up in various ways, e.g., ingenuity in shaping conventional tools to the special case, or in the invention or introduction of procedures new to this area, or the creation of particularly illuminating analogies. Entry 5's very different perspective generated some nice examples of valid comments that did not occur to those coming from the more common IL approach; while they might not be original in his or her home discipline, they qualify as such in this context.

I look forward to suggestions for improving this list, which I think is better than anything I had developed coming into this effort and has some general relevance. With the exception of $\mathrm{A}$ and $\mathrm{J}$ it provides a possible checklist for the evaluation of arguments; including them and Concision (here ensured by the context), it serves for marking argument analyses, i.e., for metaevaluation (the evaluation of evaluations). Meta-evaluation is of pedagogical interest, not only because it's what instructors do, but also because students should learn to do it on their own analyses before turning them in. However, it's pedagogically easier to teach a single checklist for both purposes, in which case one simply puts Clarity and Concision under Presentation, and awards bonus points for Originality under whatever heading it is manifested. Then the students first apply the checklist to the argument (etc.) they are analyzing, and then apply it to their own (or another's) analysis. (More on the methodology of meta-evaluation in Evaluation Thesaurus, 4th edition (Sage, 1991).)

These criteria are arguably not of equal importance, but debates about relative weights are likely to be inconclusive. For this particular task-ranking for a prize-there's a reasonable case for approximate equality, including $\mathrm{J}$. The aim of course was to try for a conclusion that was robust enough to withstand any reasonable variations in weight. Many years of experience with rating scale construction and research suggest that 'reasonable variations' in weights for the criteria would be within a 2 to 1 range, contrary to what beginners often think appropriate.

3. Representing the argument The first step with complex arguments is to provide a representation (i.e., re-presentation) that meets three conditions. (i) It must, to the extent feasible, provide a simplification or condensation that is as radical as is needed for the intended reader/audience to grasp the argument as a whole, or at least to grasp the relation of its components to one another. This can be done in various ways: (a) by describing (not condensing) the whole as a whole-i.e., by giving an overview; (b) by fitting it into a framework of a more general discussion (entry 7 did this in an original way); (c) by providing brief descriptions of various parts and relating them (i.e., a set of views); or (d) by condensing, rather than describing, the components and hence the whole. The last option tends to be preferred because it simultaneously meets the need to make it possible to deal with sub-arguments and other comments-but with long arguments one may have to do one of the first two as well, for Clarity (of type A1). Entry 1 was marginal on this-two pages for the out- 
line is hard on most readers-although its opening move, which suggested a classification scheme for the elements in the argument, was ingenious and helpful. Entry 3 would have improved its presentation by leading with its third and fourth paragraphs. (ii) Either for presentational or later purposes, one must introduce a labeling system to facilitate easy reference to elements of the argument in the course of the commentary; the choice of elements is crucial, and discussed below. (iii) The summary must constitute a valid transformation, i.e., must not introduce substantial distortions in the reasoning (this is the Structure requirement).

To do all this, one may first need to clear away some of the underbrush-for example, one may need to stipulate a meaning for some term, explain why one is going to ignore some byplay or annotation, explain how one will deal with an ambiguity or why one will adopt one interpretation when another may seem equally plausible. But it's often possible to give a 'warts and all' overview, and do the refinements en passant as you proceed with the detailed analysis. While one or two entries would have simplified life for the reader if they had done more of the brush-clearing, I did not fault this heavily since the severe length constraints made it difficult to justify or even explain the way you were doing this; the same applied to some other obviously desirable expansions such as introductions to paragraphs of detailed criticism, which would have explained just where they fitted in and how important they were.

Tree diagrams are one possible way to represent an argument-the entrants showed a nice variety of approaches-and one has to keep in mind that tree diagrams of complex arguments can be as hard to decipher as Mayan sign-language, which means their use risks losing Clarity; entry 3 showed it can be done. Allowable differences of interpretation mean that evaluating a complex tree diagram is as hard as evaluating long essays so, as we all know, they're not necessarily a boon for the evaluator (a.k.a. instructor) who can't just use a template to identify the right one, except for very simple arguments. My tentative conclusion from this exercise is that the best bet with complex arguments is a twostage approach: a brief overview which is then used as a frame on which to hang a more detailed account.

How best to label the components? Numbering each component statement ( 30 in this case), which often works well with short arguments, can get out of hand with the long ones. The entrants used different and worthwhile approaches; in my preliminary attempt, like entry 5 , I chose to use paragraphs as units because they happened to correspond to main sub-arguments-but this, like other approaches, will not always be the best one. (Are we getting into situational logic here?)

In representing the argument it is prima facie desirable to label even the parts of it that are not going to be commented on, and classify them, e.g., as 'clarification', 'an aside', 'an example of preceding point', etc., so that the evaluator or audience knows what you're doing with them and won't think you've missed them. (Of course, some moves which are presented as 'clarifications' by the arguer are in fact incorrect or obscure, and you will have to make logical or communicative comments about them.) It is also important to keep relating the thread of the critical comments to the main picture, so that the reader doesn't get bogged down in the details; entry 5 was often excellent on this. But I did little marking down on the absence of this 'infrastructure', because the entries that did not do it were putting in more detailed logical commentary instead.

4. The evaluation matrix Given here for general interest. I haven't filled in detailed scores because (i) for ranking purposes, as here, I use but haven't room to explain the technique of qualitative salience scoring (it involves only marking deviations from the norm thereby making 
differences more obvious by leaving most of the cells blank), and (ii) the reasons for particular scores are sometimes not obvious without lengthy explanation and this commentary is already much longer than the entries.

\begin{tabular}{|l|l|l|l|l|}
\hline & 1 & 3 & 5 & 7 \\
\hline Clarity (of arg't rep' $\mathrm{n}$ ) & & & & \\
\hline Clarity (of analysis) & & & & \\
\hline Structure & & & & \\
\hline Assumptions & & & & \\
\hline Correct (log'l cmts) & & & & \\
\hline Selective & & & & \\
\hline Comprehensive & & & & \\
\hline Presentation & & & & \\
\hline Perspective & & & & \\
\hline Synthesis & & & & \\
\hline Originality & & & & \\
\hline
\end{tabular}

5. Recommendation I recommend that entries 1 and 3 be regarded as tying for the prize, and that the other two be Highly Commended.

\section{Notes}

1 Note that this is quite different from Al and $A 2$, which are communications ratings by the evaluator about the analyst's writing, rather than commentary by the analyst about the original argument.

MICHAEL SCRIVEN

PACIFIC GRADUATE SCHOOL OF

PSYCHOLOGY

935 EAST MEADOW DRIVE

PALO ALTO, CA 94303

\section{Judge's Report}

\section{HENRY W. JOHNSTONE, JR. The Pennsylvania State University}

My ranking of the evaluations is the following.

\begin{tabular}{c} 
Ranking \\
\hline 1 \\
2 \\
3 \\
4
\end{tabular}

\begin{tabular}{c} 
Entry Number \\
\hline 127 \\
125 \\
121 \\
123
\end{tabular}

In explaining my preference for $\# 127$, let me begin by pointing out a slight inconsistency in the instructions for the contest. The title of your announcement is "Argument Evaluation Contest." Yet in the first sentence you say that the prize will go to the best critical analysis of the argument in question. A critical analysis might be nothing more than an examination, from the point of view of Informal Logic, of the statements, generalizations, analogies, warrants, and other implicatures put for- ward by the argument, as well as-indeed, especially - of the linkages that the argument claims to have established among these various constituents. Since, as I suspect, all of the entrants are well qualified to practise critical analysis of this sort, being perhaps mostly teachers of Informal Logic, while on the other hand I have almost no qualifications of this sort, I would be of little use as a judge under this interpretation of the contest.

But evaluation is not quite the same as critical analysis. It may include the functions of critical analysis, but it must chiefly be concerned with the discernment of values. In the case of an argument, the evaluator must ask "What concern is expressed by this argument? Does the latter succeed in implementing this concern? If not, how could its effectiveness be improved?" 
I nominate Entry Number 127 as the evaluation showing the clearest awareness of what the argument under examination is concerned about and how well it succeeds in promoting this concern. Although $\# 127$ doesn't wholly approve the argument, rejecting some of its linkages as unsound, it emphasizes the need for such an argument, and suggests how to improve it. The evaluator considers what this argument needs "to deserve support." The evaluator seems, or at least claims, to know that "the pattern of unjust discrimination still exists." He/she agrees with the author of the argument that "the most important benefit" of mandatory employment equity programs "will be just treatment of the disadvantaged." "This benefit," the evaluator goes on to say, "justifies accepting the programs which the author incompletely defends."

HENRY W. JOHNSTONE, JR. DEPARTMENT OF PHILOSOPHY

THE PENNSYLVANIA STATE UNIVERSITY UNIVERSITY PARK, PA I6802

\section{EDITORS' DECISION}

Readers can imagine the Editors' consternation on discovering the judges" rulings. Professor Scriven's top and bottom pairs are the inverse of Professor Johnstone's. The editors, themselves still not knowing the contestants' identities, undertook to break the tie. Using a fine-grained check-list aimed at identifying both the quantity and the quality of each assessment, we ended up with a verdict that scored one of Scriven's winning pair and Johnstone's top-ranked entry even, and the other two in a tie for a close second. In other words, rather than settle the matter, our judgement produced a third verdict.

In the circumstances, it seems to us folly to declare a winner. However, the contestants (if no one else) will remind us of the small matter of the prize-money of US\$100. The difficulties of judging tempted us to award $\$ 25$ each to the four judges (the two original judges and the two Editors). Instead, invoking King Solomon, we have decided to add a second $\$ 100$ to the purse, and award each of the four entrants $\$ 50$, with our thanks and congratulations for their excellence, and our gratitude for their patience.

\section{Meta-Contest}

Still, based on our own experience with this contest and also on the promptings of Michael Scriven, hinted at in his judge's verdict, we are not ready to drop the matter entirely. Instead we propose now to shift attention to another level, a different perspective.

Hereby we solicit essays based on the Argument Analysis Contest as the raw material. What we would like to receive from interested readers is your "take" on this exercise: what inferences or lessons do you think can and should be drawn from it? For instance, what does it tell us about the assessment of arguments? The "raw material" here includes the following items: the original argument and the contest rules, the analyses submitted by the contestants and published in this issue, plus the verdicts of the judges and their comments.

The best submission will receive a $\$ 100$ prize. The paper will be published in Informal Logic. Length: 2500-5000 words. The deadline for submissions is December 31, 1992. 